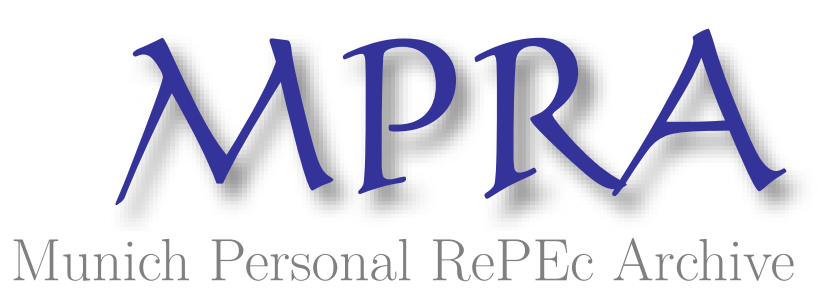

Mid-day Meal Program and Incidence of Child Labour in a Developing Economy

Chaudhuri, Sarbajit

University of Calcutta

12 May 2007

Online at https://mpra.ub.uni-muenchen.de/4367/

MPRA Paper No. 4367, posted 07 Aug 2007 UTC 


\title{
Mid-day Meal Program and Incidence of Child Labour in a Developing Economy
}

\author{
Sarbajit Chaudhuri \\ Reader \\ Department of Economics \\ University of Calcutta \\ 56A, B.T. Road \\ Kolkata 700050 \\ India.
}

\begin{abstract}
Address for communication: Dr. Sarbajit Chaudhuri, 23 Dr. P.N. Guha Road, Belgharia, Kolkata 700083, India. Tel: 91-33-541-0455 (R), 91-33-557-5082 (C.U.) Fax: 91-33-2844-1490

E-mail: sarbajitch@yahoo.com, sceco@caluniv.ac.in
\end{abstract}

(This version: May 2007)

\begin{abstract}
The present paper purports to examine the consequence of mid-day meal program and/or cash stipend scheme on the incidence of child labour in a developing economy using a three-sector general equilibrium model. It has been found that the policy may be counterproductive as it lowers both the initial incomes of the working families and the return on education. Direct cash payments to the working families instead of mid-day meal program are likely to be effective in eradicating the problem of child labour.
\end{abstract}

Keywords: Child labour, mid-day meal program, return on education, general equilibrium.

JEL classification: F10, J10, J13, I28. 


\section{Mid-day Meal Program and Incidence of Child Labour in a Developing Economy}

\section{Introduction}

The incidence of child labour is one of the major problems facing the developing world in the liberalized economic regime. The economists and policymakers are in search of policies that can bring down this problem satisfactorily. In the theoretical literature, the supply of child labour has largely been attributed to two factors: abject poverty and capital market imperfection. Basu and Van (1998) and Basu (1999) have explained child labour using the poverty argument while Ranjan (1999, 2001), Baland and Robinson (2000) and Jafarey and Lahiri (2002) emphasize the importance of capital-market imperfection as a contributing factor to inefficient child labour.

For eliminating the incidence of child labour, the World Development Report 1995 called for a multifaceted approach with programs that lessen poverty and increase income security, reduce education costs, and improve the quality of schooling. However, policy prescriptions directed towards poverty alleviation are difficult to be implemented properly due to various bottlenecks and vicious circles typical of developing economies; even if implemented, they take a long time to mitigate the problem. Despite high economic growth, resulting from implementation of economic reforms during the last two decades, poverty has increased in many liberalizing economies $^{1}$ and the incidence of child labour has not decreased satisfactorily. It is, therefore, believed that the betterment of educational opportunities and a policy of compulsory education designed for human capital formation can more effectively remove children from work.

Governments all over the world devote substantial resources to their education sector. This is especially true in developing countries. In 1995, public spending on education accounted for $15.7 \%$ of total government expenditure in developing countries (see Bedi and Garg (2000)). Furthermore, the majority of students in developing countries are educated in publicly funded and publicly managed educational institutions. According to Jimenez and Lockheed (1995), almost $90 \%$ of all primary and $70 \%$ of all secondary enrollments in developing countries are in public schools.

${ }^{1}$ See Khan (1998) and Tendulkar et al. (1996) among others. 
In the public education system in the developing economies there are provisions for the children to get stipend, free educational goods and free mid-day meals. These policies are designed to mitigate the problem of child labour by keeping them in school. Economic incentives alone are not generally very effective in increasing school attendance. However, according to ILO (1999) these schemes are extremely important in raising education levels and should be employed in the developing countries with child labour more as a means to offset the income loss incurred by sending a child to school. Incentives can be in the form of free meals to students, food to the student's family, cash stipend and free uniforms and books. These schemes are expected to lower the incidence of child labour by lowering the forgone effective child wage income as well as by raising the future earnings potential of the children attending school through human capital formation.

The present paper intends to examine the consequence of mid-day meal program and/or provision for cash stipend to school attending children on the incidence of child labour in a developing economy using a three-sector general equilibrium model. The supply function of child labour of each working family is derived from its intertemporal utility-maximizing behaviour. Sector 1 in the general equilibrium model is agriculture where child labour is used along with adult unskilled labour and capital. Sector 2 is the low-skill manufacturing sector that uses adult unskilled labour and capital. Finally, sector 3 employs skilled labour and capital to produce a high-skill commodity. In this setup, we shall examine the consequence of the mid-day meal program or cash stipend scheme on the aggregate supply of child labour in the society. We identify the different channels through which the policy affects the prevalence of the evil in the system. We have found that the policy may be counterproductive as it lowers both the initial incomes of the working families and the return to education. Direct cash payments to the working families instead of mid-day meal program are likely to be effective in eradicating the problem of child labour.

\section{Derivation of supply function of child labour}

The supply function of child labour by each working family is determined from its intertemporal utility maximizing behaviour. Let us consider a two period optimizing problem of the representative working family consisting of one adult member (the guardian) and a child. The 
guardian in the first period works in the adult labour market and earns a wage $W_{0}{ }^{2}$ In this period, he takes decision about his child's work effort and schooling. Total child time is 1, a part of which $\left(l_{C}\right)$ is sent out to work at the wage rate $W_{C}$. Non-existence of a market for loans against future earnings compels the parent to use income from child work to smooth out the family consumption $^{3}$. Time not spent on working is spent in school ${ }^{4}$. Hence $\left(1-l_{C}\right)$ is the child's schooling. There are provisions for midday meals and cash stipend for children attending school, the monetary value of which is $b$ per unit of child labour time spent in school. So, $l_{C}$ part of the child labour time earns the child wage, $\left(W_{C}\right)$, in the first period and the unskilled adult wage $(W)$ in the second period while $\left(1-l_{C}\right)$ fraction earns $b$ in the first period and the skilled wage $\left(W_{S}\right)$ in the second period. ${ }^{\mathbf{5}}$ We assume that $W_{C}>b$, otherwise no children will be sent out to work. In the presence of positive return on education, $W_{S}$ is greater than $W$. In the second period, the guardian earns nothing and lives on the income he receives from his child who has become an adult worker by this time.

We assume that the parent cares only about the lifetime family consumption and does not attach any value to the child's leisure. The utility is therefore a function of consumption levels in the two periods ( 1 and 2 ) and is represented as follows.

$U=\frac{C_{1}^{-\rho}}{-\rho}+\beta \frac{C_{2}^{-\rho}}{-\rho} \quad-1<\rho<\infty$

${ }^{2} W_{0}$ can take two values, $W$ (unskilled wage) and $W_{S}$ (skilled wage), depending on the type of the representative working household.

3 There are informal credit markets in developing countries as a substitute to missing formal credit market, but they mainly deal with short-term loans. Poor households need long-term credit to be able to substitute for the foregone earnings of their children, which is missing in the developing countries. See for example, Baland and Robinson (2000), Jafery and Lahiri (2002), Ranjan $(1999,2001)$ in this context.

4 This is a simplifying assumption that ignores the existence of non-labour non-school goers.

5 Introduction of uncertainty in securing a skilled job in the second period would be an interesting theoretical exercise. However, the major results of the model still hold if the probability in finding a high-skill job is given exogenously. 
$\beta$ is the time discount factor and $\left(\frac{1}{1+\rho}\right)$ is the constant intertemporal elasticity of substitution.

The first period's consumption $\left(C_{1}\right)$ consists of wage income of the guardian, child wage income from the working time of the child and the pecuniary value of mid-day meal and cash stipend received from child labour time spent in school i.e.,

$C_{1}=\left(W_{0}+l_{C} W_{C}+b\left(1-l_{C}\right)\right)$

The second period's consumption $\left(C_{2}\right)$ can be thought of as the sum of skilled wage of educated adult (schooled in the first period) labour and unskilled wage of uneducated adult labour (worked in the first period).

$C_{2}=\left(l_{C} W+\left(1-l_{C}\right) W_{S}\right)$

We assume that the only cost of education is the opportunity cost in terms of forgone earnings of children. $^{6}$

The guardian maximizes the lifetime utility (Equation (1)) with respect to $l_{C}$ and subject to (2) and (3). Maximization gives the following first-order condition.

$\left[\frac{\left(l_{C} W+\left(1-l_{C}\right) W_{S}\right)}{\left(W_{0}+b+l_{C}\left(W_{C}-b\right)\right)}\right]^{(1+\rho)}=\frac{\beta\left(W_{S}-W\right)}{\left(W_{C}-b\right)}$

Solving equation (4) the following child labour function by each working family is obtained.

$$
l_{C}=\frac{W_{S}-\left(W_{0}+b\right)\left\{\frac{\beta\left(W_{S}-W\right)}{\left(W_{C}-b\right)}\right\}^{1 /(1+\rho)}}{\left(W_{C}-b\right)\left\{\frac{\beta\left(W_{S}-W\right)}{\left(W_{C}-b\right)}\right\}^{1 /(1+\rho)}+\left(W_{S}-W\right)}
$$

For algebraic simplicity we consider the special case where $\rho=0$ which means a logarithmic utility function with unitary intertemporal elasticity of substitution ${ }^{7}$. The child labour supply function of the household then reduces to:

6 Here the opportunity cost of sending children to school is the effective child wage rate, $\left(W_{C}-b\right)$. One can, of course, incorporate direct schooling cost without affecting the qualitative results of the model. 
$l_{C}=\frac{W_{S}}{(1+\beta)\left(W_{S}-W\right)}-\frac{\beta\left(W_{0}+b\right)}{(1+\beta)\left(W_{C}-b\right)}$

Let us now discuss the properties of the child labour function given by (6). An increase in current income, $W_{0}$, (income from non-child source) raises both $C_{1}$ and $C_{2}$ and hence lowers $l_{C}$ following a positive income effect. An increase in the child wage rate implies an increase in the opportunity cost of education and hence leads to more child labour supply (i.e. less schooling). An increase in the pecuniary benefits from the mid-day meal program lowers the effective child wage rate, thereby leading to less child labour. Any changes in skilled and/or unskilled wages impinge on the return on education and therefore influence the guardian's decision regarding allocation of child time between his education and work. For example, an increase in skilled wage $\left(W_{S}\right)$ or a decrease in unskilled wage $(W)$ makes education more attractive and raises schooling time of the child thereby lowering the supply of child labour by the household.

\section{The General Equilibrium Analysis}

We consider a small open economy with three sectors. Sector 1 produces an agricultural commodity, $X_{1}$, using adult unskilled labour $(L)$, child labour $\left(L_{C}\right)$ and capital $(K)$. The capitaloutput ratio in sector $1, a_{K 1}$, is assumed to be technologically given. ${ }^{\mathbf{8}}$ Sector 2 uses unskilled labour and capital to produce a low-skill commodity, $X_{2} \cdot{ }^{9}$ Finally, sector 3 produces a high-skill commodity, $X_{3}$, with the help of skilled labour $(S)$ and capital. Commodity prices, $P_{i}$ s, are given by the small open economy assumption. Competitive markets, CRS technologies with diminishing marginal productivities of inputs and full-employment of resources are assumed.

${ }^{7}$ See Ranjan (1999) for a similar treatment.

8 Although this is a simplifying assumption it is not completely without any basis. Agriculture requires inputs like fertilizers, pesticides, weedicides etc. which are to be used in recommended doses. Now if capital is used to purchase those inputs, the capital-output ratio becomes constant technologically. However, labour and capital are substitutes and the production function displays the property of constant returns to scale in these two inputs.

9 Even if sector 2 is allowed to use child labour the results of model hold under different sufficient conditions. See footnote 15 for more details. 
The usual price-unit cost equality conditions relating to the three sectors are as follows.

$W a_{L 1}+W_{C} a_{C 1}+R a_{K 1}=P_{1}$

$W a_{L 2}+R a_{K 2}=P_{2}$

$W_{S} a_{S 3}+R a_{K 3}=P_{3}$

where $a_{j i} \mathrm{~s}$ are input-output ratios; and, $R$ is the return to capital.

Complete utilization of adult unskilled labour, child labour, capital and skilled labour imply the following four equations, respectively.

$a_{L 1} X_{1}+a_{L 2} X_{2}=L$

$a_{C 1} X_{1}=L_{C}$

$a_{K 1} X_{1}+a_{K 2} X_{2}+a_{K 3} X_{3}=K$

$a_{S 3} X_{3}=S$

where $L, K$ and $S$ denote exogenously given endowments of adult labour, capital and skilled labour, respectively. $L_{C}$ is the endowment of child labour which is endogenously determined.

Both unskilled and skilled working families are potential suppliers of child labour and their current wage incomes $\left(W_{0}\right)$ are $W$ and $W_{S}$, respectively. Using equation (6) the aggregate child labour supply in the economy is obtained as follows.

$L_{C}=\left(\frac{1}{1+\beta}\right)\left[L\left\{\frac{W_{S}}{\left(W_{S}-W\right)}-\frac{\beta(W+b)}{\left(W_{C}-b\right)}\right\}+S\left\{\frac{W_{S}}{\left(W_{S}-W\right)}-\frac{\beta\left(W_{S}+b\right)}{\left(W_{C}-b\right)}\right\}\right]$

\section{Comparative Statics}

The general equilibrium structure consists of eight equations ((7) - (14)) and the same number of variables, namely; $W, W_{C}, W_{S}, R, X_{1}, X_{2}, X_{3}$ and $L_{C}$. This is an indecomposable production structure. So factor prices depend on both commodity prices and factor endowments. Given the child wage rate, sectors 1 and 2 together can be viewed as a miniature Heckscher-Ohlin system as they use both adult unskilled labour and capital. It is sensible to assume that sector 1 is more adult 
labour-intensive than sector 2 with respect to capital. Totally differentiating equations (7) - (14) and solving by Cramer's rule the following proposition can be established. ${ }^{\mathbf{1 0}}$

Proposition 1: A mid-day meal program and/or cash stipend to school attending children leads to (i) a fall in the adult wage; (ii) an increase in the child wage; and, (iii) a decrease in the skilled wage rate. The policy improves the skilled-unskilled wage inequality iff the high-skill sector is capital-intensive (in a special sense) relative to the low-skill sector.

Proposition 1 can be verbally explained as follows. An increase in the pecuniary value of mid-day meal and/or cash stipend, ceteris paribus, lowers the effective child wage, $\left(W_{C}-b\right)$, which in turn lowers the aggregate supply of child labour initially. This raises the child wage rate, $W_{C}$. As the child wage rate rises, the effective price of commodity 1 , net of cost on child labour, falls. This produces a Stolper-Samuelson effect in the Heckscher-Ohlin subsystem (HOSS). The return to capital, $R$, rises while the adult unskilled wage, $W$, falls as sector 1 is more adult labourintensive than sector 2 with respect to capital. A Rybczynski-type effect takes place subsequently and leads to a contraction of sector 1 and an expansion of sector $2 .^{11}$ The amount of capital released by sector 1 is inadequate for the expansion of sector 2 . So sector 3 also has to release capital to the expanding sector 2 . Sector 3 contracts for scarcity of capital. The demand for skilled labour falls that lowers the skilled wage, $W_{S}$. What happens to the skilled-unskilled wage inequality depends on the rates of decrease in $W_{S}$ and $W$ which in turn depend on the distributive shares of capital in the two sectors. If the high-skill sector (sector 3) is capital-intensive in a special sense ${ }^{\mathbf{1 2}}$ the increase in cost on capital input in sector 3 is more than that in the low-skill sector (sector 2), which in turn, implies a decrease in the relative wage inequality.

${ }^{10}$ This has been proved in Appendix I.

11 See Appendix I for detailed mathematical proof.

12 Here sectors 2 and 3 use two different types of labour. However, there is one intersectorally mobile input which is capital. So, these two sectors cannot be classified in terms of factor intensities which is usually done in the Hechscher-Ohlin-Samuelson model. Despite this, a special type of factor intensity classification in terms of the relative distributive shares of the mobile factor i.e. capital can be made for analytical purposes. The sector in which this share is higher relative to the other may be considered as capital-intensive in a special sense. See Jones and Neary (1984) for details. 
We are now going to analyze the consequence of the mid-day meal program/cash stipend scheme on the incidence of child labour in the society. Totally differentiating equation (14) and using the results of proposition 1 the following proposition can be established. ${ }^{\mathbf{1 3}}$

Proposition 2: The mid-day meal program and/or cash stipend scheme for the school attending children will increase the supply of child labour in the economy if (i) sector 3 is capital-intensive; and, (ii) the effective child wage does not fall. Direct cash payments to the working families are likely to be effective in mitigating the problem of child labour.

We explain proposition 2 in the following way. The aggregate supply of child labour in the economy depends negatively on the initial incomes of the families as well as on the return on education while it depends positively on the effective child wage and the endowments of the two types of adult labour. As stated in proposition 1, the mid-day meal program lowers both the skilled wage, $W_{S}$, and the adult unskilled wage, $W$, but raises the child wage rate, $W_{C}$. However, the outcome on the effective child wage, $\left(W_{C}-b\right)$, is uncertain. All these factors affect the supply of child labour in different ways. First, the supply of child labour by each family rises via the negative income effect as the initial incomes from non-child source of both types of working families have decreased. Secondly, the supply of child labour increases if the return on education falls. The wage inequality and hence the return on education will fall if sector 3 is capitalintensive. Finally, the consequence of any changes in the effective child wage on the supply of child labour is ambiguous. However, if the effective wage of child labour, $\left(W_{C}-b\right)$, does not fall, the incidence of child labour in the economy rises as all the three effects work together to raise the supply of child labour. Even when $\left(W_{C}-b\right)$ falls, the incidence of child labour may increase if the sum of the first two effects dominates over the effective child wage effect.

On the contrary, direct cash payments to the child labour supplying families will raise their initial incomes and exert downward pressure on the supply of child labour through the positive income effect. There will be no other effects as the wage rates do not change. Hence this policy is likely to be capable in lowering the prevalence of the evil in the system.

13 This has been proved in Appendix II. 


\section{Concluding remarks}

This paper has explained how economic incentive schemes designed to keep children in school might fail in controlling the child labour problem in the society. The family supply function of child labour has been derived from the intertemporal utility maximizing behaviour of the working households which send some of their children to the job market for consumption smoothing owing to non-existence of a market for loans against future earnings. Then the aggregate supply function of child labour has been derived and a three-sector general equilibrium model has been developed for the purpose of analysis. The interesting result is that economic incentive schemes like the mid-day meal program and provision for cash stipend might exert an upward pressure on the incidence of child labour by lowering both the return on education and the initial incomes of the working population. Therefore, the gravity of the problem may increase due to both negative income effect and decreased return on education even if the effective child wage falls. Direct cash payments to the working families are likely to be effective in the present setup because the policy raises the initial incomes of these families including the cash transfer and lowers the supply of child labour through the positive income effect.

There are certain assumptions of the model that may seem to be restrictive. The model presupposes that the quality of education is good and that the children attending school in the present period will get jobs in the high-skill sector in future ${ }^{\mathbf{1 4}}$. However, the quality of basic education in the developing countries is generally unsatisfactory and there is also unemployment of educated workers. Besides, the assumption that child labour is used only in the agricultural sector is simplifying. ${ }^{\mathbf{1 5}}$ Despite this simplicity and abstraction, the results of the theoretical analysis presented in this paper seem to be interesting because its results question the desirability of the mid-day meal program and/or provision for cash stipend in eliminating the problem of child labour in the developing countries.

14 Introduction of uncertainty in securing a skilled job in the second period would be an interesting theoretical exercise. It may, however, be checked that the results of the model hold if the probability in finding a high-skill job is given exogenously.

15 This assumption may be justified on the ground that more than 70 per cent of economically active children in the developing countries are engaged in agriculture and allied sectors and less than 9 per cent are involved in manufacturing (ILO (2002) report). However, even if sector 2 uses child labour the results of this paper hold under different sufficient conditions involving relative intensities in which child labour and other two inputs are used in the first two sectors. 


\section{Appendix I:}

Totally differentiating equations (7) - (9) and using envelope conditions the following expressions are obtained.

$\theta_{L 1} \hat{W}+\theta_{C 1} \hat{W}_{C}+\theta_{K 1} \hat{R}=0$

$\theta_{L 2} \hat{W}+\theta_{K 2} \hat{R}=0$

$\theta_{S 3} \hat{W}_{S}+\theta_{K 3} \hat{R}=0$

where: $\theta_{j i}=$ distributive share of the $j$ th input in the $i$ th sector; and, ' $\wedge$ '= proportional change.

Totally differentiating equations (10) - (14), collecting terms and simplifying we get the following expressions.

$$
\begin{aligned}
& \bar{S}_{L L} \hat{W}+\lambda_{L 1} S_{L C}^{1} \hat{W}_{C}+\bar{S}_{L K} \hat{R}+\lambda_{L 1} \hat{X}_{1}+\lambda_{L 2} \hat{X}_{2}=0 \\
& \bar{S}_{K L} \hat{W}+A_{2} \hat{R}+A_{1} \hat{W}_{S}+\lambda_{K 1} \hat{X}_{1}+\lambda_{K 2} \hat{X}_{2}=0 \\
& \left(S_{C L}^{1}+E\right) \hat{W}+\left(S_{C C}^{1}-F\right) \hat{W}_{C}+G \hat{W}_{S}+\hat{X}_{1}=-H \hat{b}
\end{aligned}
$$

[Note that we have used $\hat{X}_{3}=-S_{S S}^{3} \hat{W}_{S}-S_{S R}^{3} \hat{R}$ from (13)]

where,

$$
\begin{aligned}
& \bar{S}_{L L}=\left(\lambda_{L 1} S_{L L}^{1}+\lambda_{L 2} S_{L L}^{2}\right)<0, \bar{S}_{K L}=\lambda_{K 2} S_{K L}^{2}>0, \\
& \bar{S}_{K K}=\left(\lambda_{K 2} S_{K K}^{2}+\lambda_{K 3} S_{K K}^{3}\right)<0 ; \bar{S}_{L K}=\lambda_{L 2} S_{L K}^{2}>0 ; \\
& A_{1}=\lambda_{K 3}\left(S_{S K}^{3}+S_{K S}^{3}\right)>0 ; A_{2}=\left(\bar{S}_{K K}-\lambda_{K 3} S_{S K}^{3}\right)<0 \\
& A=\frac{W_{S} \cdot W}{(1+\beta) L_{C}\left(W_{S}-W\right)^{2}}>0, B=\frac{\beta}{(1+\beta) L_{C} W_{C}}>0 ; \\
& D=\frac{\beta}{(1+\beta) L_{C}\left(W_{C}-b\right)^{2}}>0 ; E=(-A(L+S)+B L W) ; \\
& \left.F=D W_{C}\left[(W+b) L+\left(W_{S}+b\right) S\right)\right]>0 ; G=\left(A(L+S)+B S W_{S}\right)>0 ; \\
& \left.H=D b\left[\left(W+W_{C}\right) L+\left(W_{S}+W_{C}\right) S\right)\right]>0 ;
\end{aligned}
$$

$S_{j i}^{k}=$ the degree of substitution between factors $j$ and $i$ in the $k$ th sector, $j, i=L, L_{C}, K, S$; and, $k=1,2,3$. For example, $S_{L C}^{1} \equiv\left(W_{C} / a_{L 1}\right)\left(\partial a_{L 1} / \partial W_{C}\right), S_{L L}^{1} \equiv\left(W / a_{L 1}\right)\left(\partial a_{L 1} / \partial W\right)$ etc. $S_{j i}^{k}>0$ for $\quad j \neq i ; \quad$ and, $\quad S_{j j}^{k}<0 ;\left(S_{L L}^{1}+S_{L C}^{1}\right)=0 \Rightarrow S_{L L}^{1}=-S_{L C}^{1} ; \quad$ and, 
$\left(S_{L L}^{2}+S_{L K}^{2}\right)=0 ;\left(S_{S S}^{3}+S_{S K}^{3}\right)=0$ etc. $\lambda_{j i}=$ proportion of the $j$ th input employed in the $i$ th sector.

Equations (A.1) - (A.6) are arranged in the following matrix form.

$\left[\begin{array}{cccccc}\theta_{L 1} & \theta_{C 1} & \theta_{K 1} & 0 & 0 & 0 \\ \theta_{L 2} & 0 & \theta_{K 2} & 0 & 0 & 0 \\ 0 & 0 & \theta_{K 3} & \theta_{S 3} & 0 & 0 \\ \bar{S}_{L L} & \lambda_{L 1} S_{L C}^{1} & \bar{S}_{L K} & 0 & \lambda_{L 1} & \lambda_{L 2} \\ \bar{S}_{K L} & 0 & A_{2} & A_{1} & \lambda_{K 1} & \lambda_{K 2} \\ \left(S_{C L}^{1}+E\right) & \left(S_{C C}^{1}-F\right) & 0 & G & 1 & 0\end{array}\right]\left[\begin{array}{c}\hat{W} \\ \hat{W}_{C} \\ \hat{R} \\ \hat{W}_{S} \\ \hat{X}_{1} \\ \hat{X}_{2}\end{array}\right]=\left[\begin{array}{c}0 \\ 0 \\ 0 \\ 0 \\ 0 \\ -H \hat{b}\end{array}\right]$

Solving (A.8) by Cramer's rule we get the following expressions.

$$
\begin{aligned}
& \hat{W}=\left(\frac{\hat{b}}{\Delta}\right)\left(\theta_{S 3} \theta_{C 1} \theta_{K 2}|\lambda|_{L K} H\right) ; \\
& \hat{W}_{C}=-\left(\frac{\hat{b}}{\Delta}\right)\left(\theta_{S 3}|\theta|_{L K}|\lambda|_{L K} H\right) ; \\
& \hat{R}=-\left(\frac{\hat{b}}{\Delta}\right)\left(\theta_{S 3} \theta_{C 1} \theta_{L 2}|\lambda|_{L K} H\right) ; \\
& \hat{W}_{S}=\left(\frac{\hat{b}}{\Delta}\right)\left(\theta_{K 3} \theta_{C 1} \theta_{L 2}|\lambda|_{L K} H\right) ; \text { and, } \\
& \left(\hat{W}_{S}-\hat{W}\right)=\left(\frac{\left.\hat{b} H \theta_{C 1}|\lambda|_{L K}\right)\left(\theta_{K 3}-\theta_{K 2}\right)}{\Delta}\right. \\
& \hat{X}_{1}=\left(\frac{H \hat{b}}{\Delta}\right)\left[\lambda_{L 1} \lambda_{K 2}|\theta|_{L K} S_{L C}^{1}+\theta_{C 1} \theta_{L 2} \theta_{K 3} \lambda_{L 2} A_{1}+\theta_{C 1} \theta_{S 3}\left\{\theta_{L 2}\left(\bar{S}_{L K} \lambda_{K 2}-\lambda_{L 2} A_{2}\right)\right.\right. \\
& \hat{X}_{2}=-\left(\frac{H \hat{b}}{\Delta}\right)\left[\lambda_{L 1} \lambda_{K 1} \theta_{S 3}|\theta|_{L K} S_{L C}^{1}+\theta_{C 1} \theta_{L 2} \theta_{K 3} \lambda_{L 1} A_{1}+\theta_{C 1} \theta_{S 3}\left\{\theta_{L 2}\left(\bar{S}_{L K} \lambda_{K 1}-\lambda_{L 1} A_{2}\right)\right.\right. \\
& \left.\left.-\theta_{K 2}\left(\bar{S}_{L L} \lambda_{K 1}-\lambda_{L 1} \bar{S}_{K L}\right)\right\}\right]
\end{aligned}
$$

where, 


$$
\begin{gathered}
\begin{array}{c}
\Delta=-\theta_{K 3} \theta_{C 1} \theta_{L 2}\left\{B S W_{S}|\lambda|_{L K}+A_{1} \lambda_{L 2}\right\}-\theta_{S 3} \theta_{C 1} \theta_{L 2}\left(\bar{S}_{L K} \lambda_{K 2}-A_{2} \lambda_{L 2}\right) \\
+\theta_{S 3}|\theta|_{L K}\left\{\left(S_{C C}^{1}-F\right)|\lambda|_{L K}-\lambda_{K 2} \lambda_{L 1} S_{L C}^{1}\right\} \\
-\theta_{S 3} \theta_{C 1} \theta_{K 2}\left\{\left(S_{C L}^{1}+B L W\right)|\lambda|_{L K}-\left(\lambda_{K 2} \bar{S}_{L L}-\lambda_{L 2} \bar{S}_{K L}\right)\right\} \\
+A(L+S) \theta_{C 1}|\lambda|_{L K}\left(\theta_{K 2}-\theta_{K 3}\right)
\end{array} \\
\left.\begin{array}{c}
|\lambda|_{L K}=\left(\lambda_{L 1} \lambda_{K 2}-\lambda_{K 1} \lambda_{L 2}\right)>0 ; \text { and }, \\
|\theta|_{L K}=\left(\theta_{L 1} \theta_{K 2}-\theta_{K 1} \theta_{L 2}\right)>0
\end{array}\right\}
\end{gathered}
$$

(Note that $|\lambda|_{L K},|\theta|_{L K}>0$ as sector 2 is more capital-intensive than sector 1 with respect to adult unskilled labour).

Using (A.7) and (A.17) from (A.16) it follows that

$$
\Delta<0 \text { if } \theta_{K 3}>\theta_{K 2} \text {. }
$$

However, $\theta_{K 3}>\theta_{K 2}$ is only a sufficient condition for $\Delta$ to be negative.

Using (A.7), (A.16) and (A.17) from (A.9) - (A.15) we can obtain the following results.

(i) $\hat{W}<0$ when $\hat{b}>0$;

(ii) $\hat{W}_{C}>0$ when $\hat{b}>0$;

(iii) $\hat{R}>0$ when $\hat{b}>0$;

(iv) $\hat{W}_{S}<0$ when $\hat{b}>0$;

(v) $\hat{X}_{1}<0$ when $\hat{b}>0$;

(vi) $\hat{X}_{2}>0$ when $\hat{b}>0$.

(vii) $\left(\hat{W}_{S}-\hat{W}\right)<0$ when $\hat{b}>0$ iff $\theta_{K 3}>\theta_{K 2}$. 


\section{Appendix II:}

We use equation (14) to examine the impact of the mid-day meal program on the incidence of child labour in the economy. Totally differentiating equation (14) we get

$$
\begin{gathered}
\hat{L}_{C}=\hat{W}[A(L+S)-B W L]-\hat{W}_{S}\left[A(L+S)+B W_{S} S\right]+\hat{W}_{C} D W_{C}\left[(W+b) L+\left(W_{S}+b\right) S\right] \\
-H \hat{b}
\end{gathered}
$$

A little manipulation yields

$$
\begin{array}{r}
\hat{L}_{C}=-A(L+S)\left(\hat{W}_{S}-\hat{W}\right)-L B W \hat{W}-S B W_{S} \hat{W}_{S}+\hat{W}_{C} D W_{C}\left[(W+b) L+\left(W_{S}+b\right) S\right] \\
-H \hat{b}
\end{array}
$$

Using (A.9) - (A.13), the expression (A.20) may be rewritten as follows.

$$
\begin{array}{r}
\hat{L}_{C}=-\left(\frac{\theta_{C 1} H|\lambda|_{L K}}{\Delta}\right)\left[\left(\theta_{K 3}-\theta_{K 2}\right) A(L+S)+B\left(W_{S} S \theta_{K 3} \theta_{L 2}+W L \theta_{S 3} \theta_{K 2}\right)\right] \hat{b} \\
-H \hat{b}\left[1+\left(\frac{\theta_{S 3}|\theta|_{L K}|\lambda|_{L K} F}{\Delta}\right)\right]
\end{array}
$$

From (A.21) it follows that $\hat{L}_{C}>0$ when $b>0$ if (i) $\theta_{K 3}>\theta_{K 2}$; and,

(ii) $\left[1+\left(\frac{\theta_{S 3}|\theta|_{L K}|\lambda|_{L K} F}{\Delta}\right)\right] \leq 0$.

So, the incidence of child labour increases owing to the mid-day meal program and/or school enrollment subsidy under the sufficient conditions: (i) $\theta_{K 3}>\theta_{K 2}$; and, $\left[1+\left(\frac{\theta_{S 3}|\theta|_{L K}|\lambda|_{L K} F}{\Delta}\right)\right] \leq 0$

Condition (i) implies that sector 3 is capital-intensive relative to sector 2 while condition (ii) suggests that the effective child wage does not fall. However, the aggregate supply of child labour may increase even if the effective child wage falls. 


\section{References:}

Basu, K. and Van, P.H. (1998): 'The economics of child labour', American Economic Review $88(3), 412-427$.

Basu, K. (1999): 'Child labour: cause, consequence, and cure, with remarks on international labour standards', Journal of Economic Literature 37 (September), 1083-1119.

Baland, J. and Robinson, J.A. (2000): 'Is child labour inefficient?', Journal of Political Economy, 108(4), 663-679.

Bedi, A.S. and Garg, A. (2000): 'The effectiveness of private versus public schools: the case of Indonesia', Journal of Development Economics 61, 463-494.

ILO. (2002): 'A Future Without Child Labour?', International Labour Conference, $90^{\text {th }}$ Session June 2002, International Labour Office, Geneva.

Jafarey, S. and Lahiri, S. (2002): 'Will Trade Sanctions Reduce Child Labour? The Role of Credit Markets', Journal of Development Economics 68(1), 137-156.

Jimenez, E. and Lockheed, M. (1995): 'Public and private secondary education in developing countries: a comparative study', World Bank Discussion Paper, no. 309. The World Bank, Washington, DC.

Jones, R.W. and P. Neary (1984): 'Positive theory of international trade', in: R.W. Jones and P. B. Kenen, eds., Handbook of Development Economics, Vol. 1 (North-Holland, Amsterdam) 1-62. Khan, A.R. (1998): 'The impact of globalization in South Asia', in: A.S. Bhalla ed., Globalization, Growth and Marginalization (Macmillan, UK).

Ranjan, P. (1999): 'An Economic Analysis of Child Labour', Economic Letters 64, 99-105.

Ranjan, P. (2001): 'Credit Constraints and the Phenomenon of Child Labour', Journal of Development Economics 64, 81-102.

Tendulkar, S., D.K. Sundaram, and L.R. Jain (1996): Macroeconomic Policies and Poverty in India 1966-67 to 1993-94, Manuscript (ILO, New Delhi.). 